$$
\begin{aligned}
& \text { العزوم الطقيلية في المحركات الحثية أحادية الطور وتأثيرها } \\
& \text { على الضوضاء والاهتزازات الصادرة }
\end{aligned}
$$

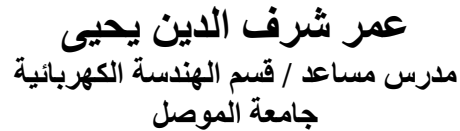

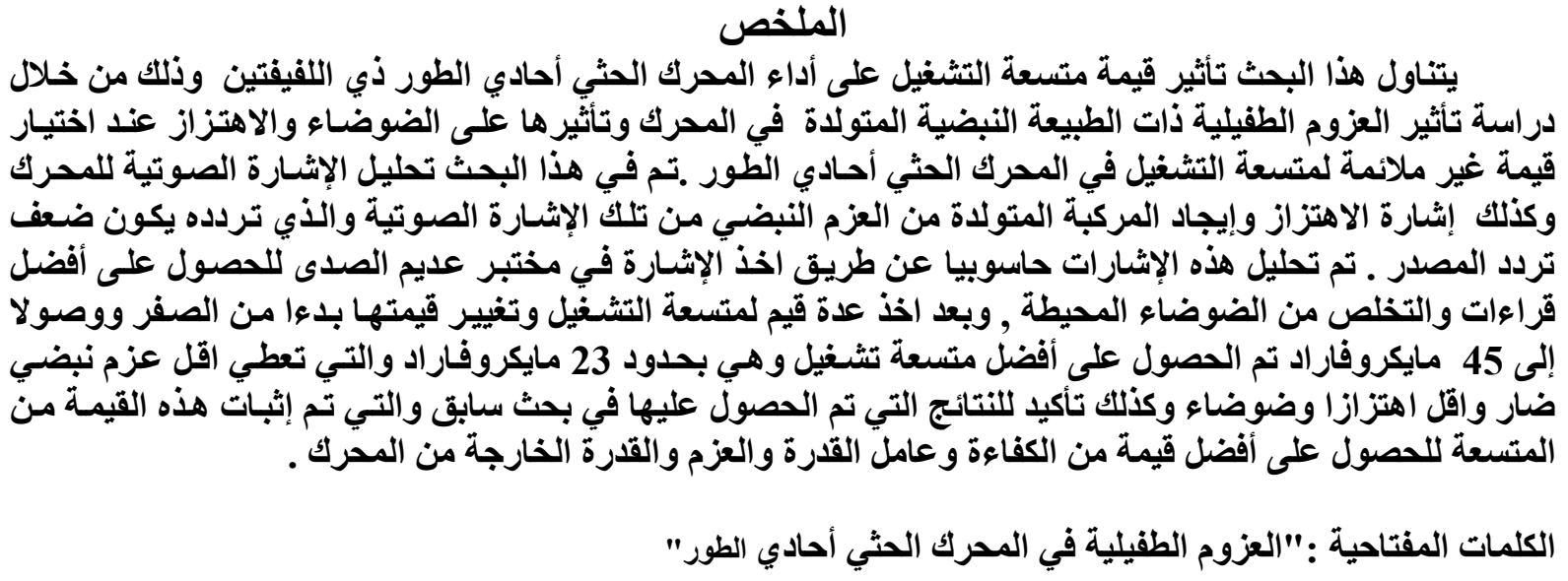

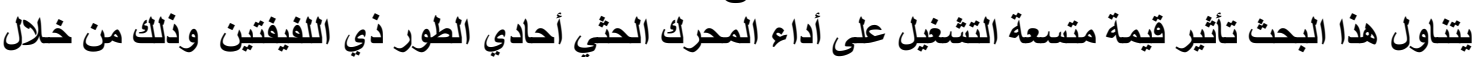

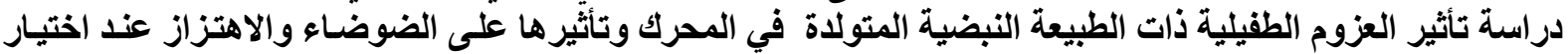

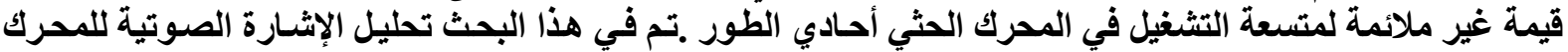

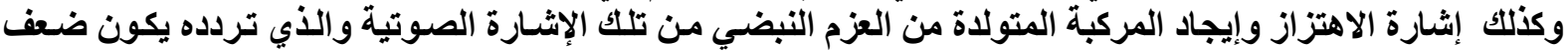

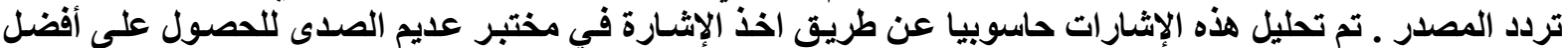

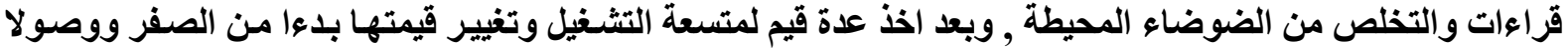

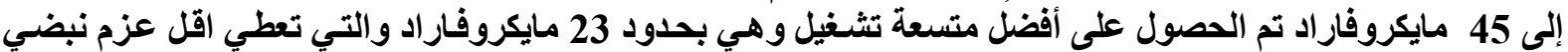

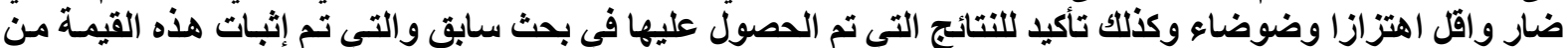

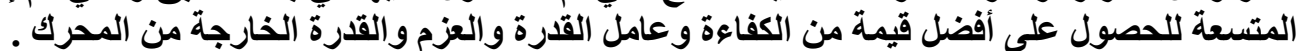

$$
\text { الكلمات المفتاحية :"العزوم الطفيلية في المحرك الحثي أحادي الطور" }
$$

\title{
Parasitic Torques of single phase induction motors and its effect on the generated noise and vibration
}

\author{
Omar Sharaf AL-Deen Yehya \\ Assist . Lecturer / Electrical Engineering \\ University of Mosul
}

\begin{abstract}
This Paper presents the effects of the Parasitic Torques in a single phase induction motor, on the Vibration and Noise that's generated from choosing unsuitable value of running capacitor. In this research a computer program has been developed of the motor Sound. The sound signal is measured by using a sound level meter and then it is transmitted to the computer through a data acquisition card and then the signal has been analyzed. In addition to that the Vibration signal has been analyzed. Experimental results has been obtained in the Anechoic Chamber Laboratory, It has been found that the optimum value of the running capacitor for this induction motor was $23 \mu \mathrm{f}$.This gives minimum Parasitic Torques whose frequency is twice the input source frequency, and therefore minimum noise and vibration caused by this Parasitic Torque has been obtained.
\end{abstract}

Key words: "Parasitic Toque for single phase induction motor" 
إن الدحرك الحثي الأحسادي الطور السـوي ( single phase induction motor with running

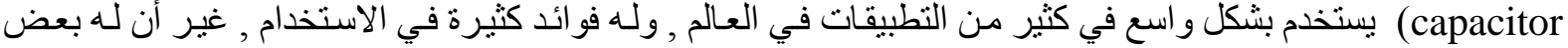

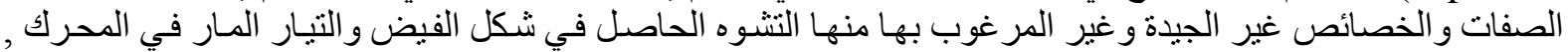

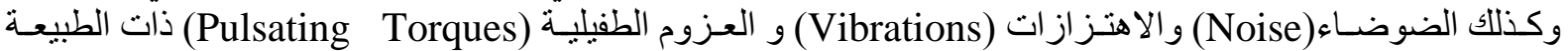

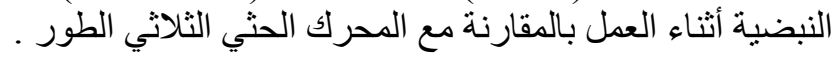

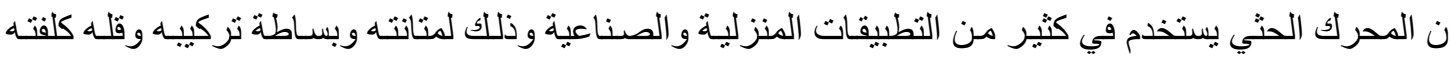

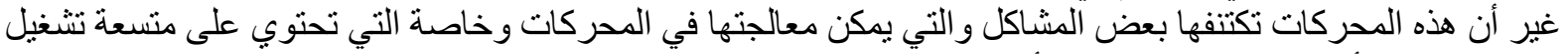

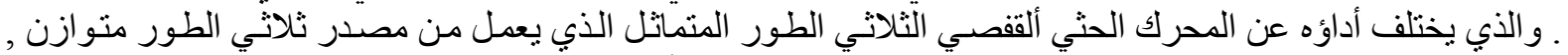

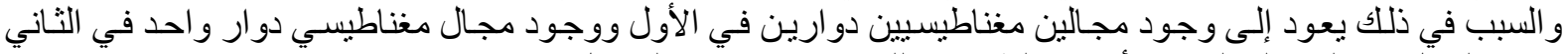
ويبين الثكل(1) المحرك الحثي الأحادي الطور ذا اللفيفتين مع متسعة التشغيل.

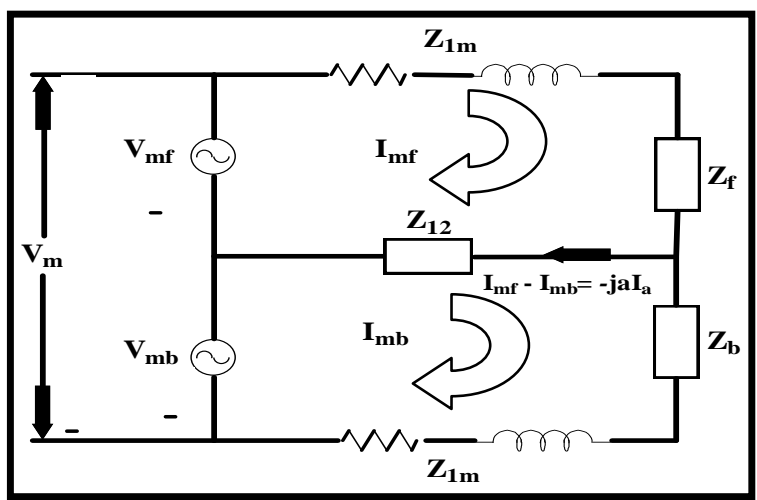

النكل (2) الدائرة المكافئة لمحرك حثي أحادي الطور ذي منسعة تشغيل

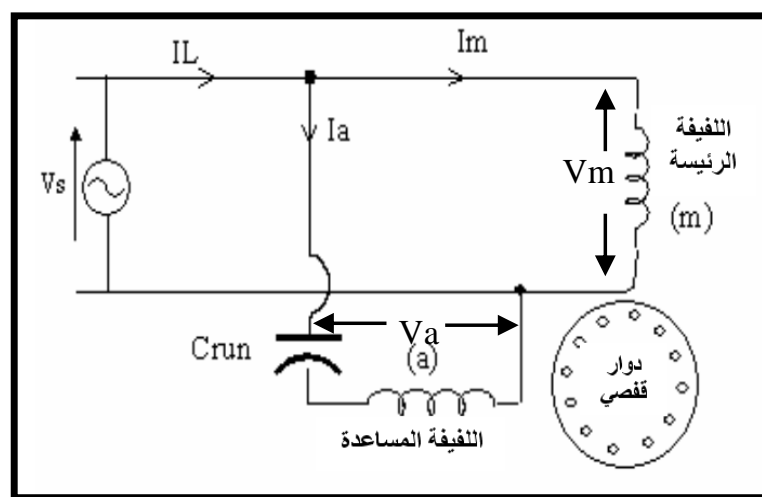

الثكل (1 ) المحرك الحثي أحادي الطور

ذي اللفيفتين مع متسعة التشغيل

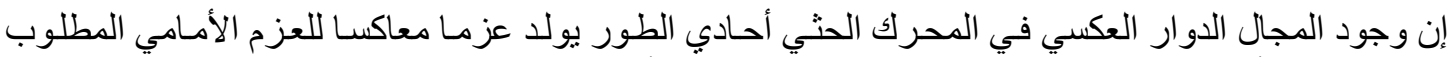

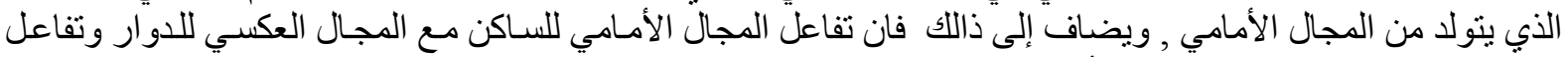

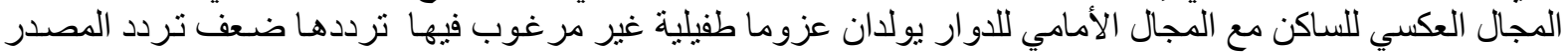

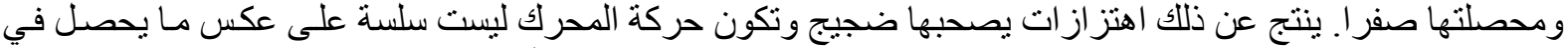
المحرك الثلاثي الطور المتو ازن. ويبين الثكل (2) الدائرة المكافئة لمحرك حثي أحادي الطور ذي متسعة تشنيل [1] [2]

تم في هذا البحث تحليل الإشارة الصوتية للمحرك الحثي الأحادي الطور بالإضافة إلى إنارة الاهتزاز وذللك عن طريق جهازين الأول مقياس مستوى الصوت (sound level meter) و الثاني مقياس الاهنز الإزات (vibration meter)

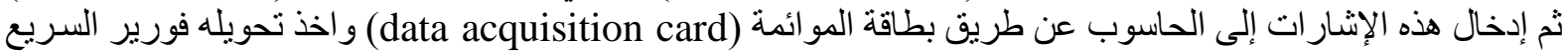

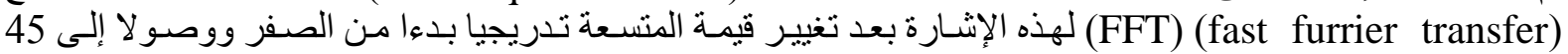

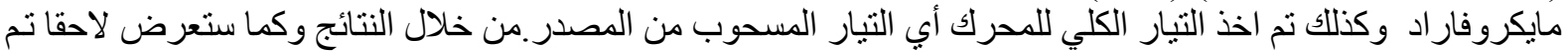

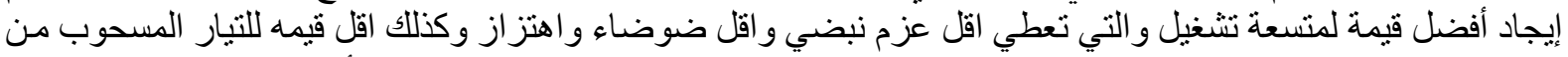

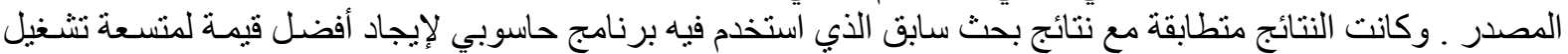

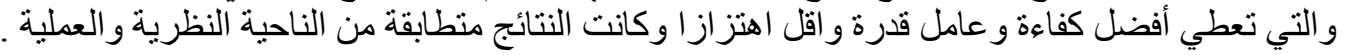

2- العزم الطفيلي و الضوضاء و الاهتز از في المحرك الحثي أحادي الطور من الناحية الكهربائية:

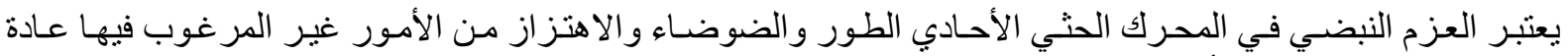

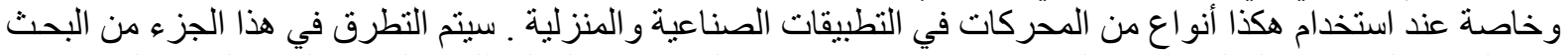

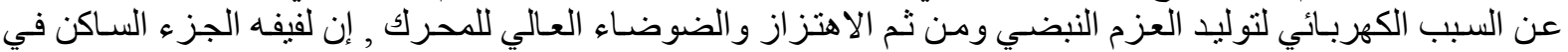




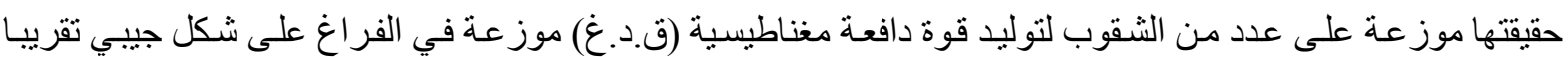

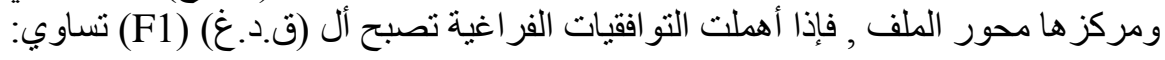

$F_{1}\left(t_{1}, \theta\right)=F_{1(\text { peak })}(t) \cos \theta$

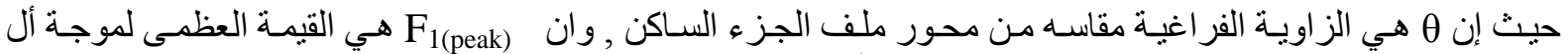

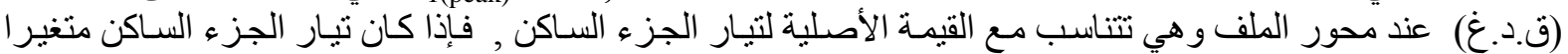
جيبيا مع الزمن فان Feak) تنغير كذلك كما في الثكل (3) وكما في المعادلة التالية:

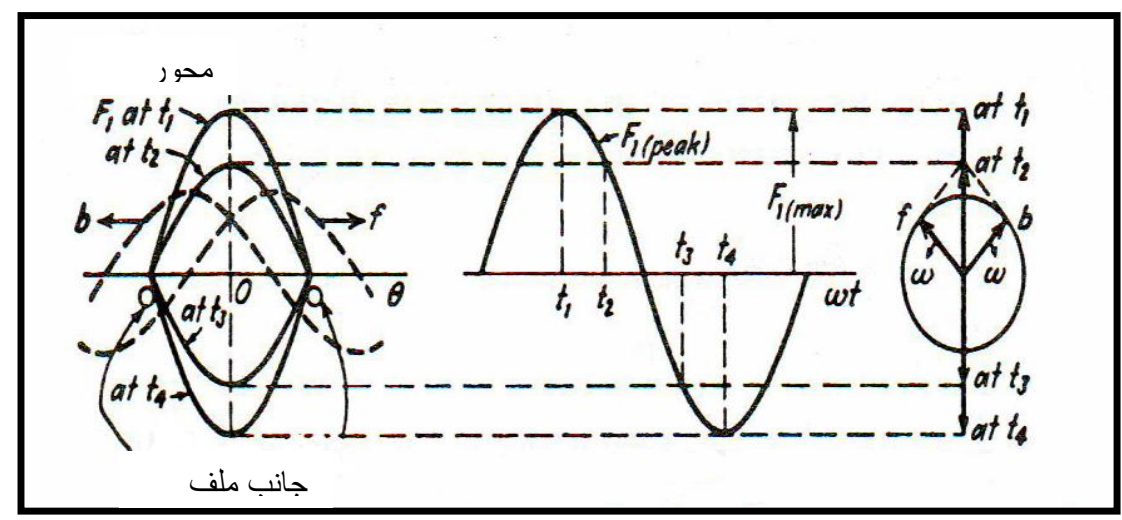

النكل (3) موجات أل ق.د.غ في محرك حثي أحادي الطور

$F_{1(\text { peak })}(t)=F_{1(\max )} \cos \left(w_{s} t\right)$

$F_{1}(t, \theta)=F_{1(\max )} \cos \left(w_{s} t\right) \cos \theta$

إذ أن w w هي السرعة الز اوية المصدر

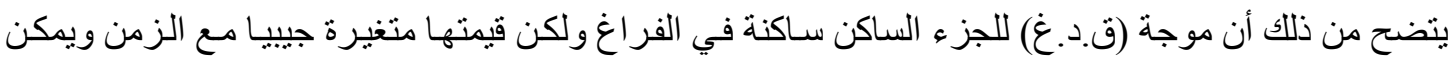

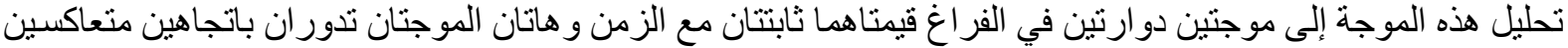
عند السر عة النز امنية وكما مبين في المعادلة التالية : $F_{1}(t, \theta)=\frac{1}{2} F_{1(\max )} \cos \left(\theta-w_{s} t\right)+\frac{1}{2} F_{1(\max )} \cos \left(\theta+w_{s} t\right)$

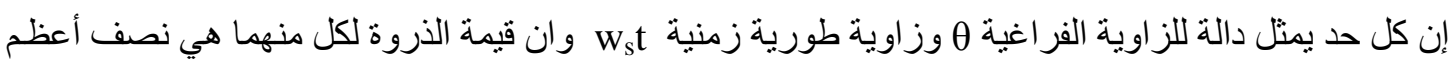

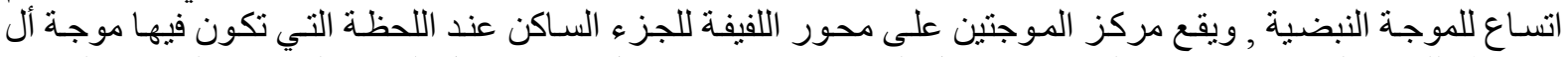

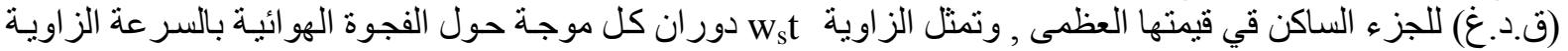

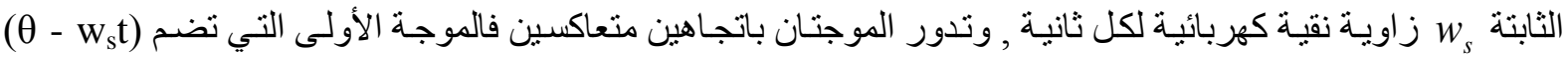

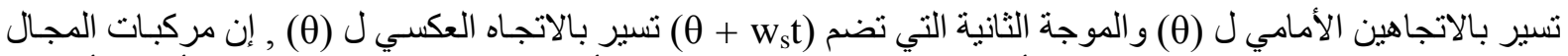

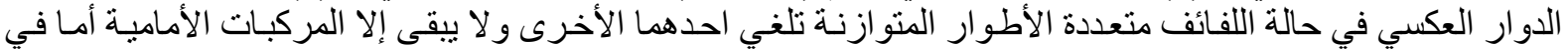

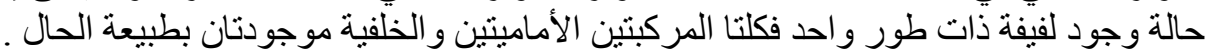

إن كلا من مركبتي أل (ق.د.غ ع) تولد عزما حثيا مركبا إلا أن العزمين التابعين يكونـان باتجاهين متعاكسين فإذاذا

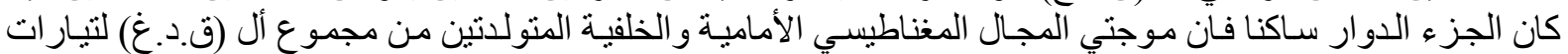

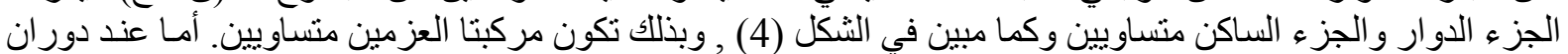

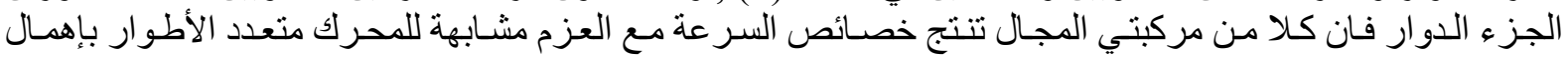

الممانعة التسربية للجزء الساكن وكما مبين في الثكل (5).

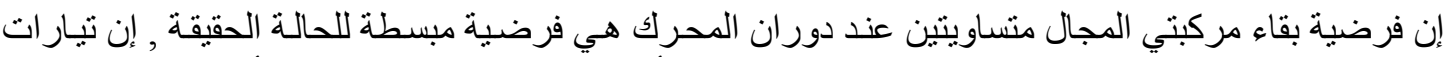

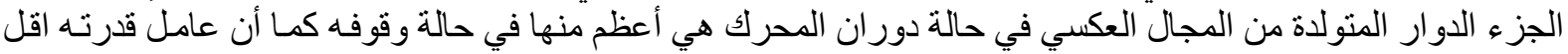




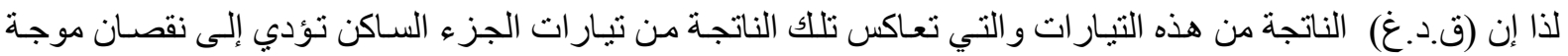

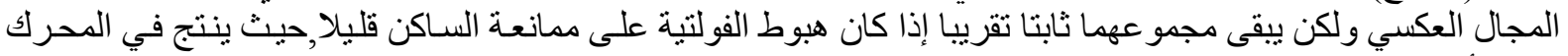

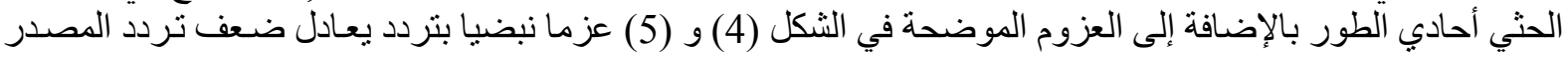

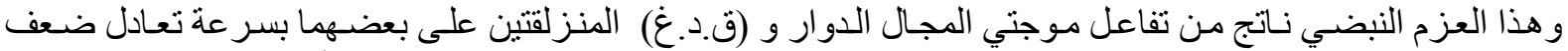

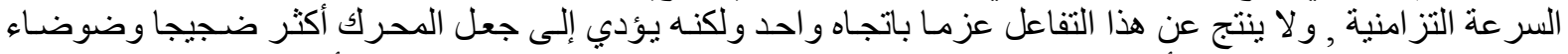

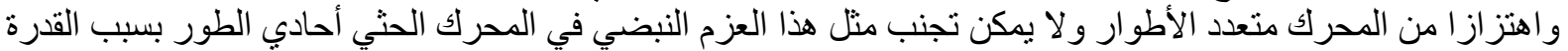

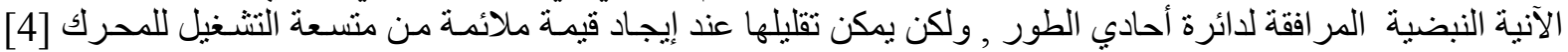

.[6] [5]

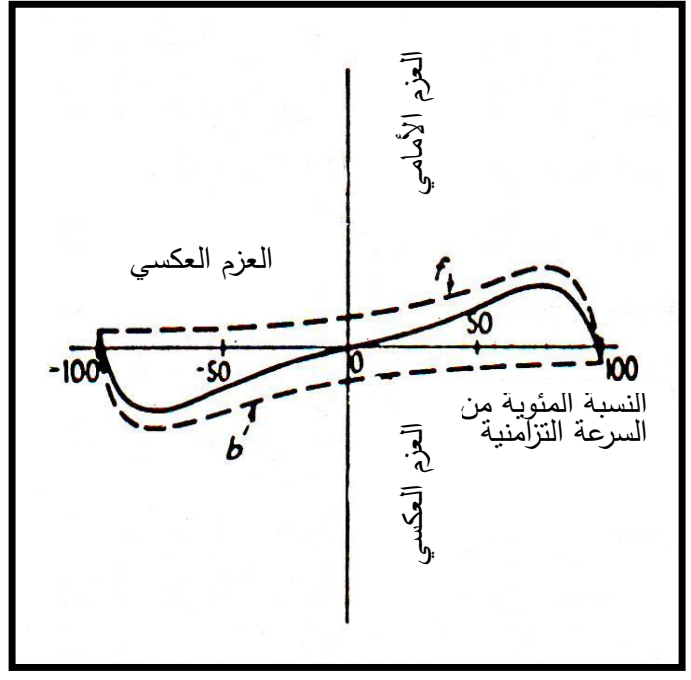

الثكل (5) التغيير في المجالين أثناء الدوران

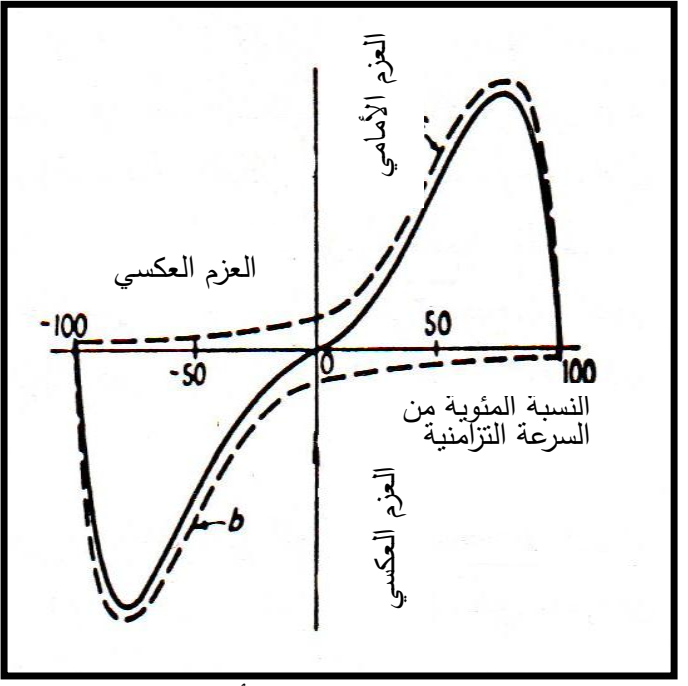

الثكل (4) تساوي المجالين الأمامي و العكسي

3ـ العزم النبضي و الضوضاء والاهنز از في المحرك الحني أحادي الطور من الناحية الميكانيكية:

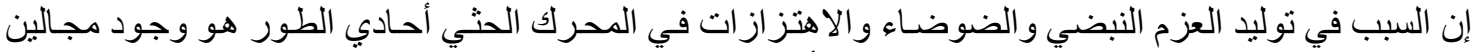

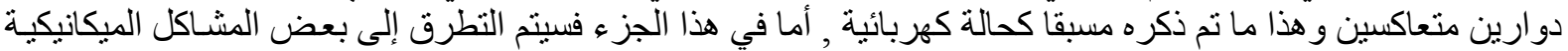

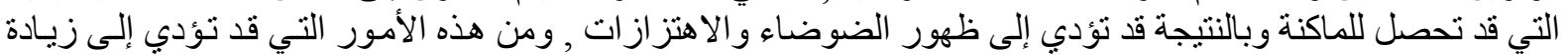

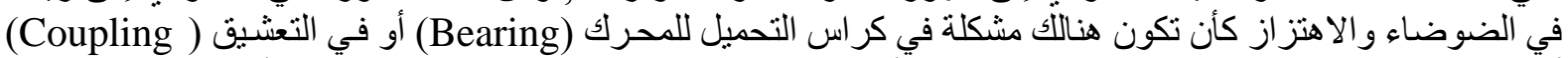

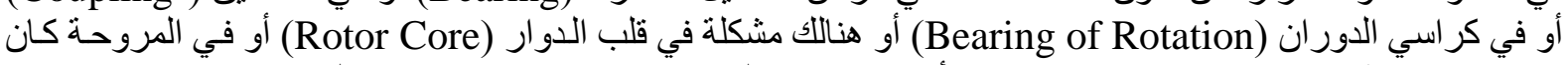

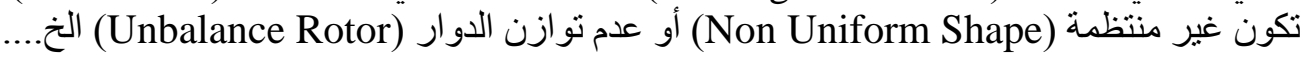

تحدث الاهنزازات و الضوضـاء بسبب كسر احد نوصبلات الدوار (Broken Rotor Bars) أو فقدان احد

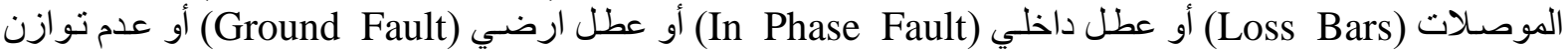

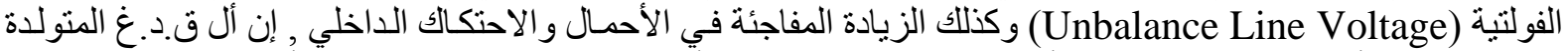

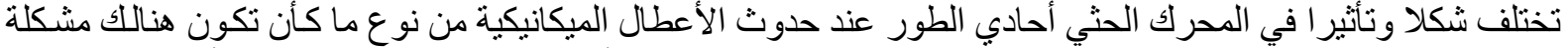

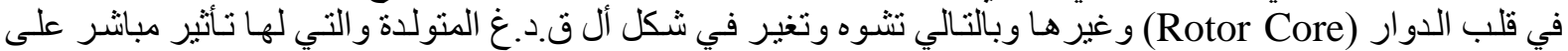

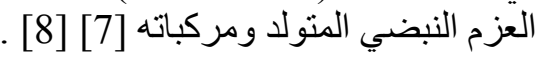

4- القيمة المثلى من منسعة التشغيل للمحرك الحثي أحادي الطور:

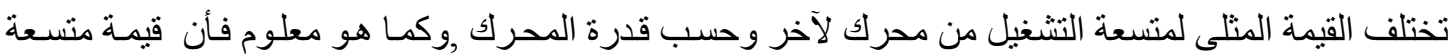

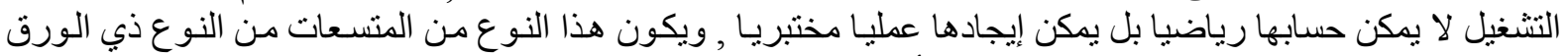

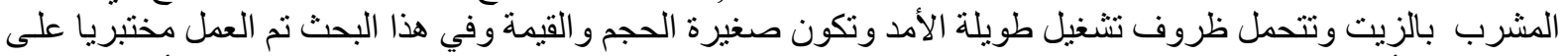

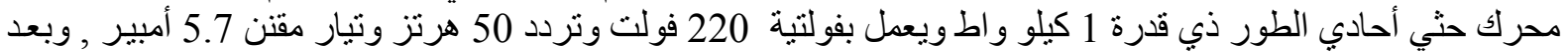

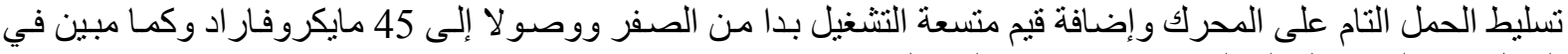
الثكل (6) الدائرة العملية لتغيير قيمة متسعة التشغيل . 


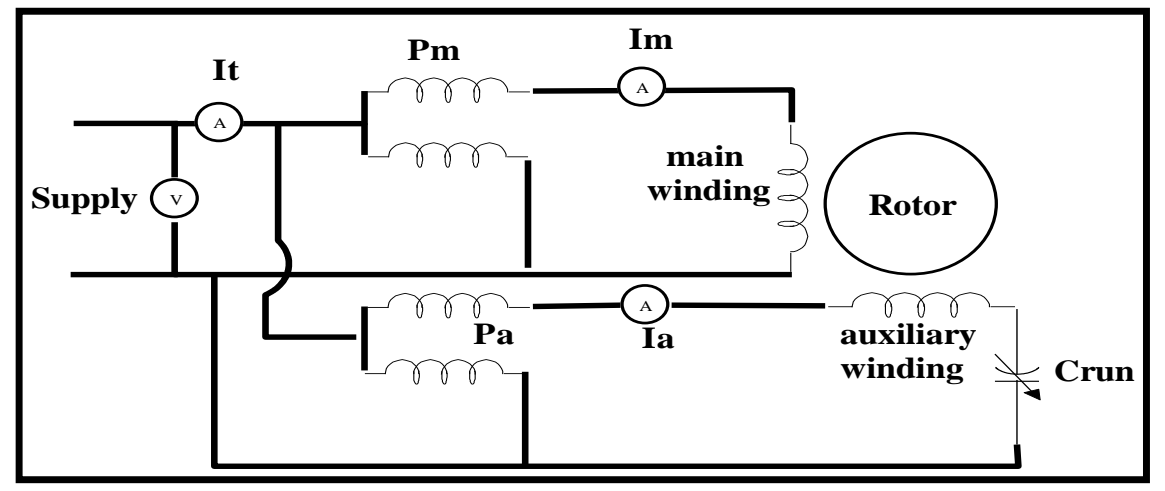

الثكل (6) يمثل الدائرة العملية لتغيير قيمة متسعة التشغيل

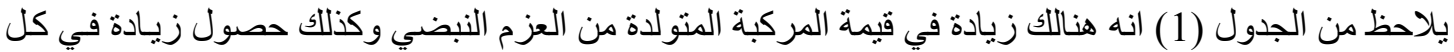

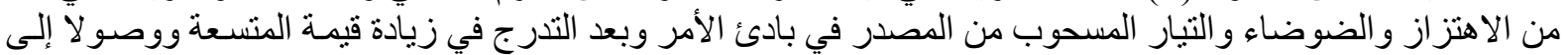

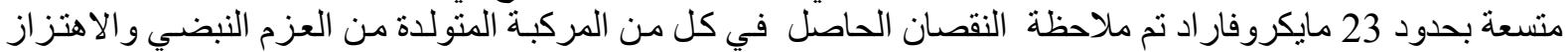

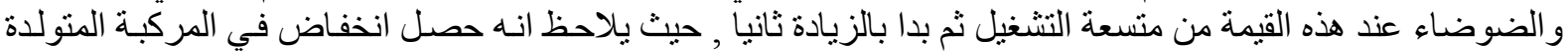

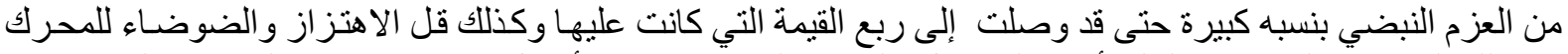

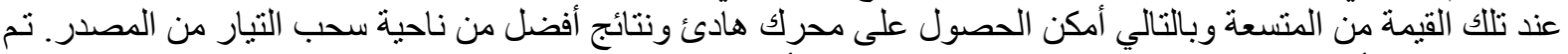

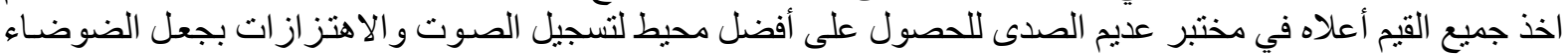
المحيطة قريبه من الصفر داخل هذا النوع من المختبر ات.

الجدول (1) تغير الضوضاء والاهتزازات مع متسعة التشغيل

\begin{tabular}{|c|c|c|c|c|}
\hline$C(\mu f)$ & 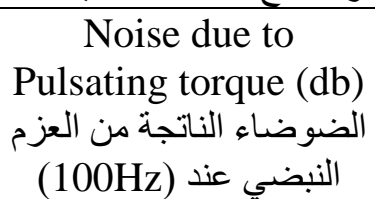 & $\begin{array}{l}\text { Vibration } \\
\text { ( الاهتزاز الكلي } \\
\text { peak peak - }\end{array}$ & $\begin{array}{l}\text { Noise Level } \\
\qquad(\mathrm{db}) \\
\text { الضوضاء الكلية }\end{array}$ & $\operatorname{It}(\mathrm{A})$ \\
\hline 0 & 33.3 & 42.3 & 72 & 5.5 \\
\hline 9 & 19.4 & 41.6 & 71 & 4.8 \\
\hline 18 & 8.63 & 38.1 & 69.5 & 4.3 \\
\hline 23 & 7.13 & 37.7 & 69.5 & 4 \\
\hline 27 & 7.63 & 39 & 72.1 & 3.9 \\
\hline 36 & 15.57 & 44 & 74 & 4.2 \\
\hline 45 & 28.11 & 50 & 75 & 4.7 \\
\hline
\end{tabular}

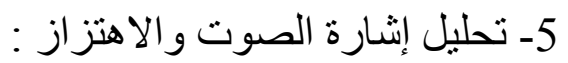

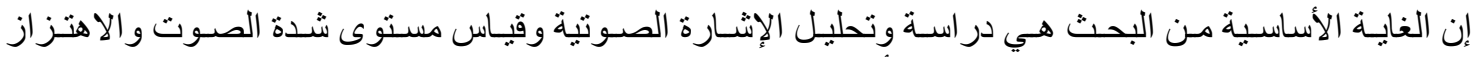

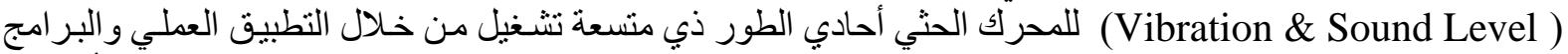

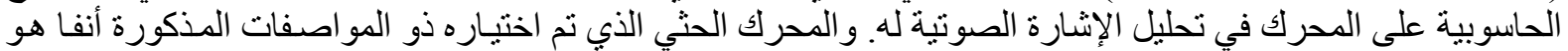

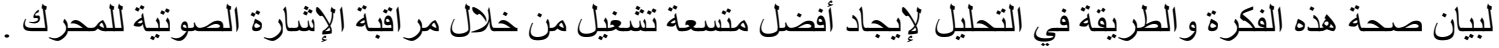

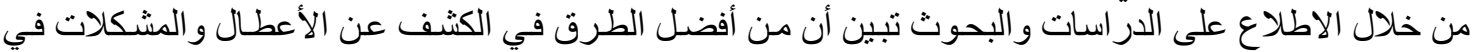

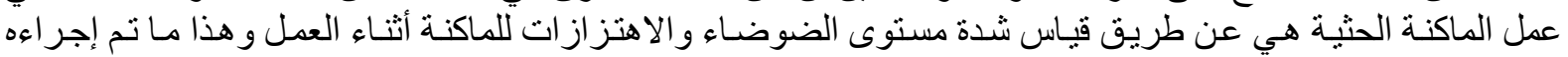

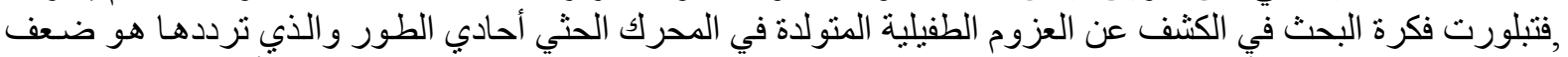

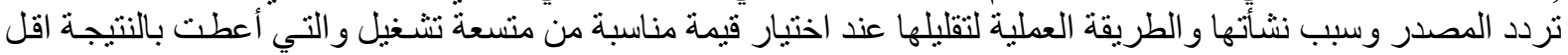

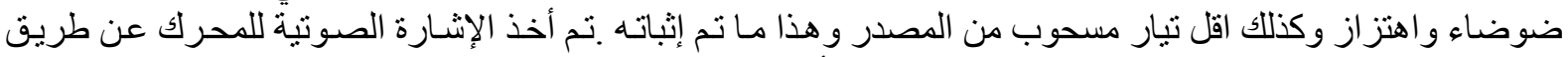

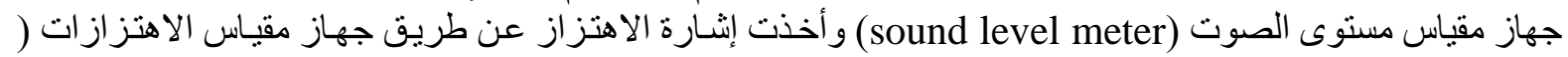

. (vibration meter model 205

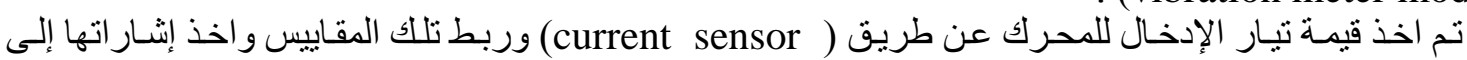

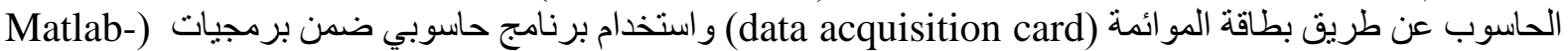

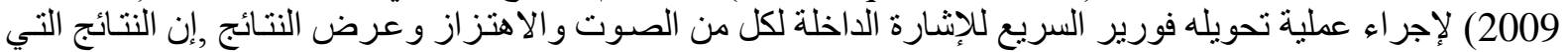


تم التوصل إليها في الجدول (1) هي مـأخوذة من الجزء العملي عند تشـيل المحرك الحثي أحسادي الطور ذي متسعة التشغيل مختبريا .

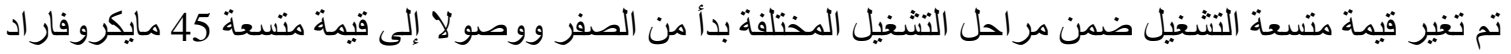

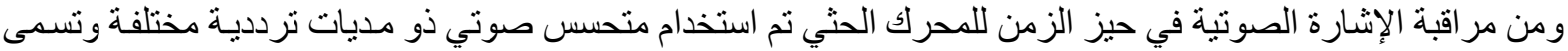

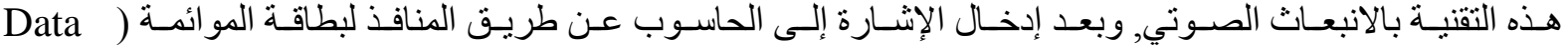

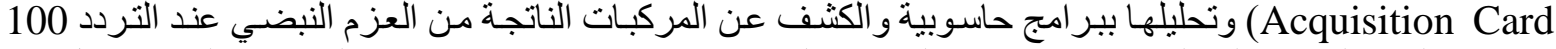

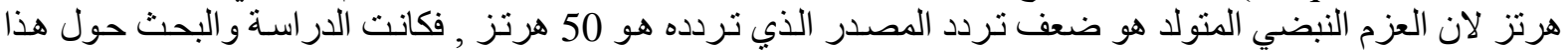

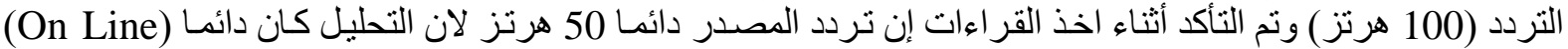

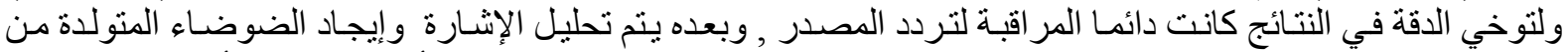

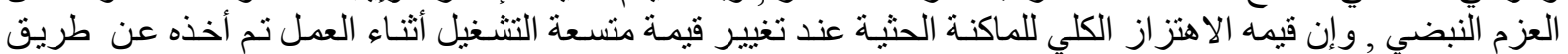

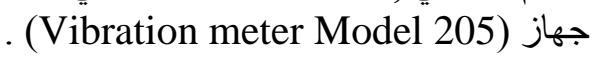

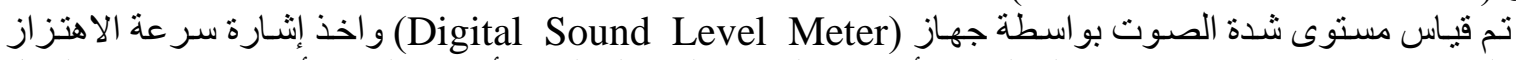

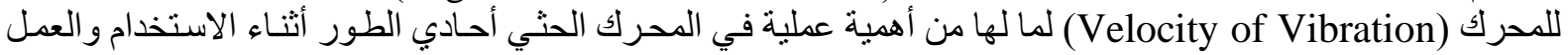

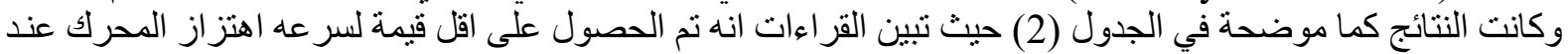

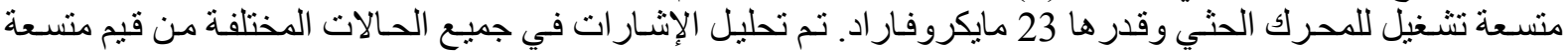
التشغيل و عند التردد 100 هرتز و وإيجاد أل (FFT) لها.

\begin{tabular}{|c|c|c|c|}
\hline $\mathrm{C}(\boldsymbol{\mu} \mathbf{f})$ & $\begin{array}{c}\text { Peak Value } \\
\text { Vibration Velocity } \\
(\mathrm{mm} / \mathrm{sec}) \\
\text { سرعة الاهنز }\end{array}$ & $\begin{array}{l}\text { R.m.s Velocity } \\
\text { (mm/sec peak) }\end{array}$ & 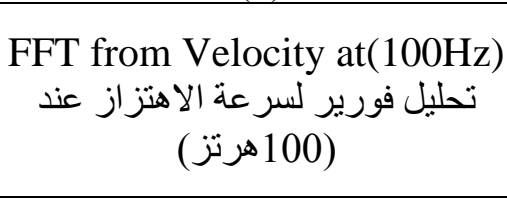 \\
\hline 0 & 3.41 & 2.411 & 0.561 \\
\hline 9 & 3.346 & 2.365 & 0.535 \\
\hline 18 & 3.01 & 2.128 & 0.493 \\
\hline 23 & 2.87 & 2.02 & 0.425 \\
\hline 27 & 3.31 & 2.34 & 0.494 \\
\hline 36 & 3.666 & 2.59 & 0.502 \\
\hline 45 & 4.33 & 3.06 & 0.591 \\
\hline
\end{tabular}

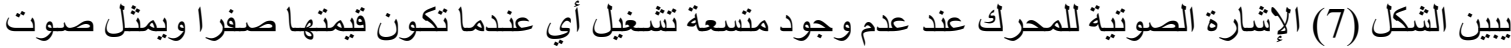

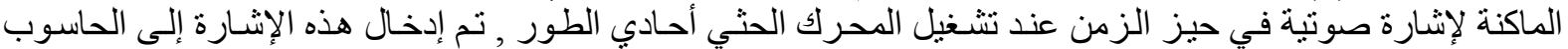

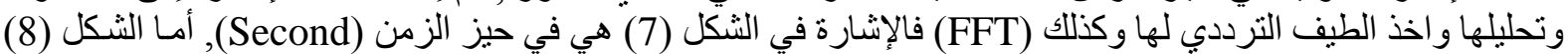

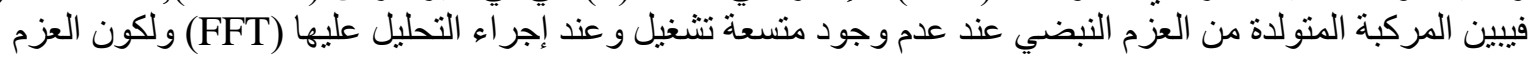

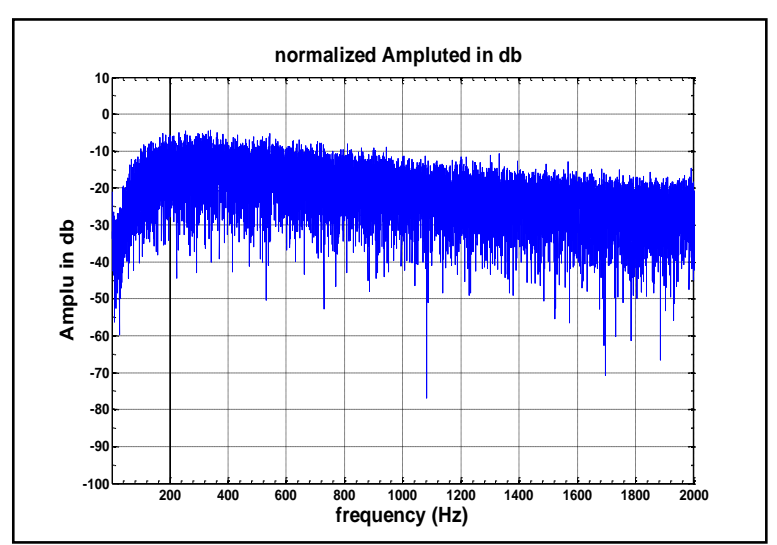

الثكل (8) المركبة المتولدة من العزم النبضي عند إجر اء التحليل عليها (FFT)

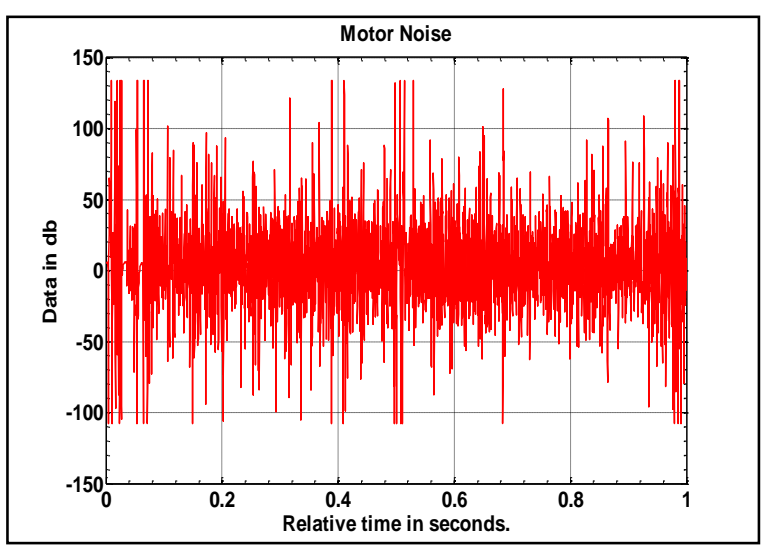

الثكل (7) الإشارة الصوتية للمحرك

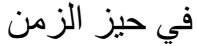




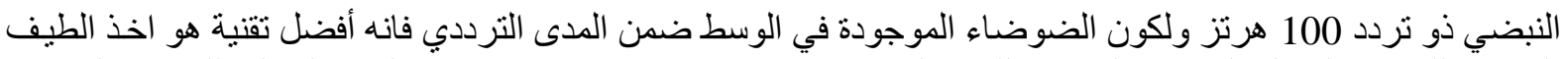

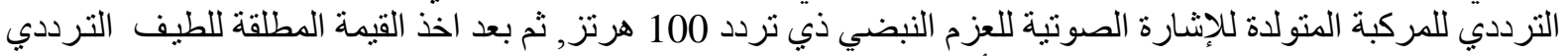

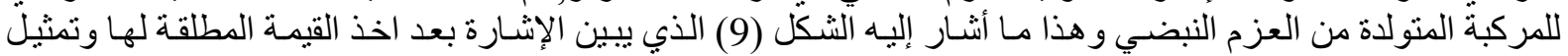

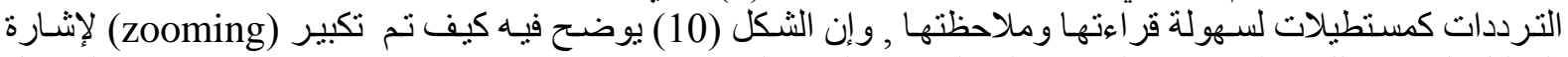

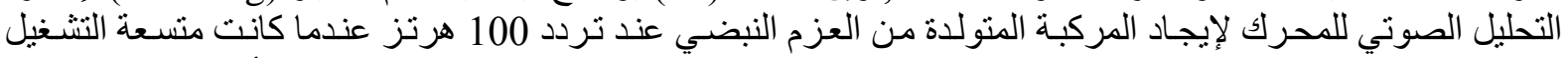

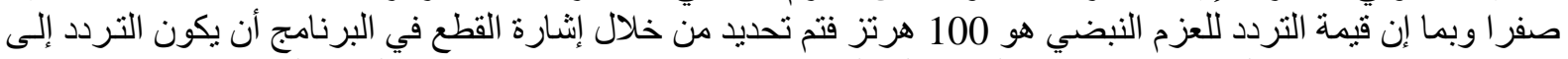

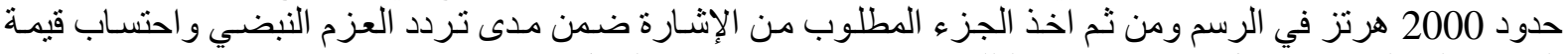

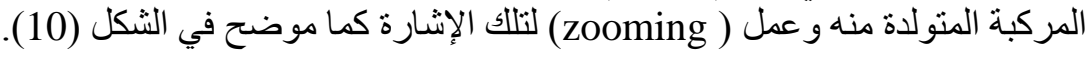

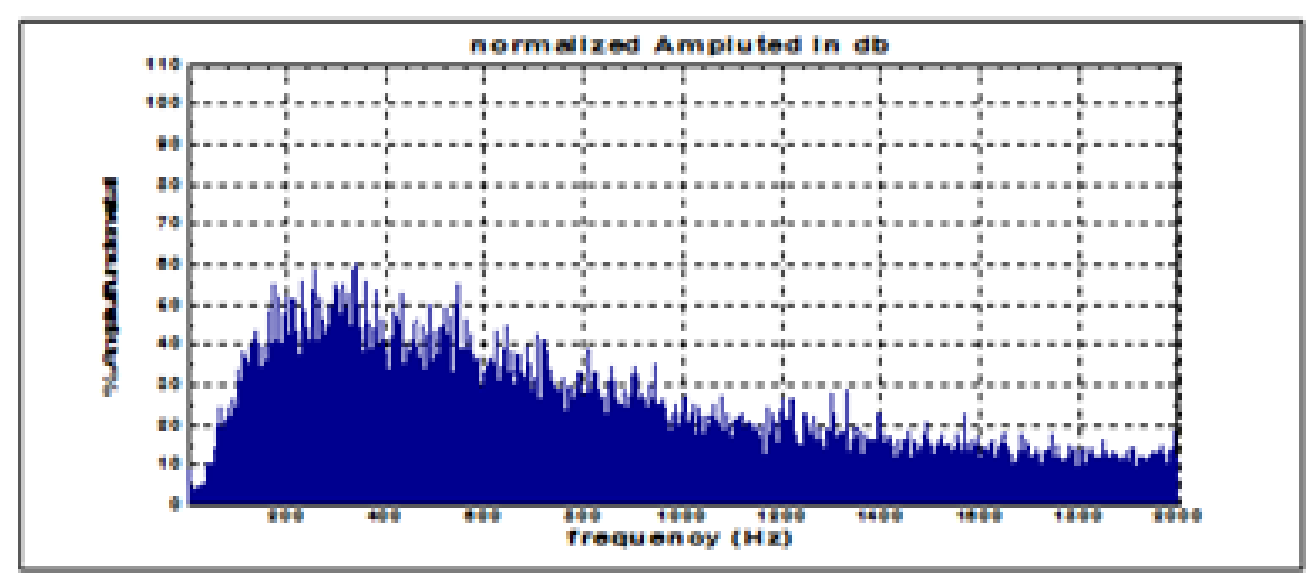

الشكل (9) الإشارة (FFT) بعد اخذ القيمة المطلقة لها

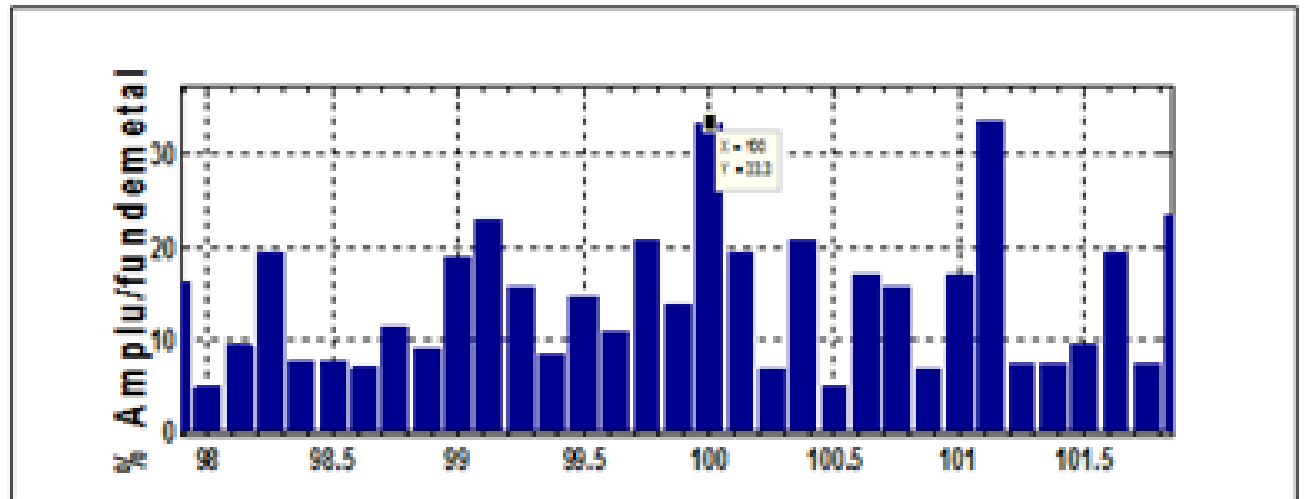

الثكل (10) تكبير لإشارة التحليل الصوتية لإيجاد المركبة المتولدة من العزم النبضي

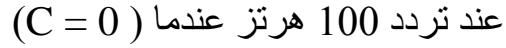

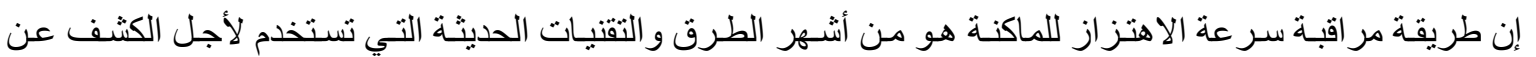

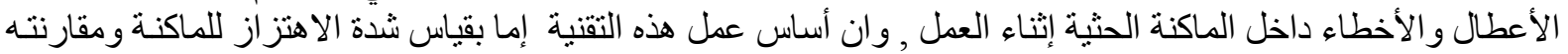

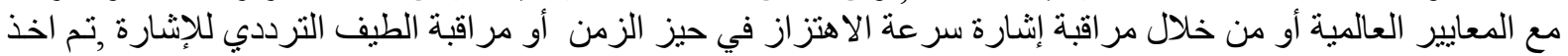

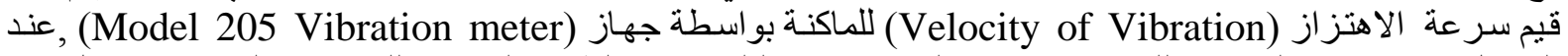

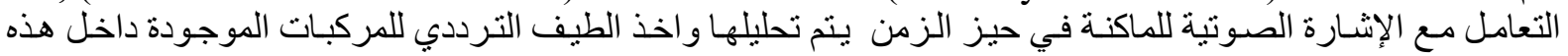

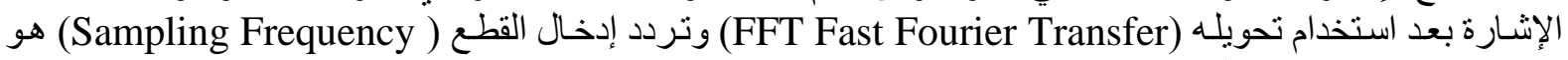

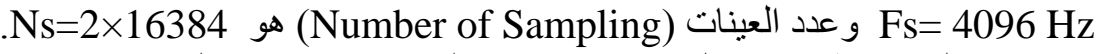

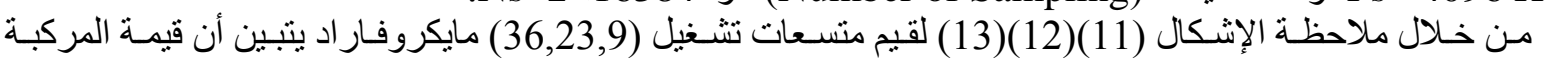

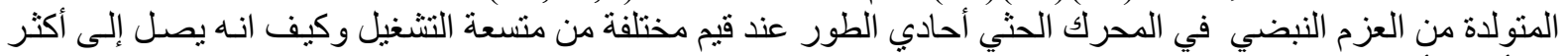
من أربعه أضعاف قيمته كما في قيمة متسعة تشغيل (36) مايكروفار الدي عند عدم اختيار القيمة المناسبة من متسعة التشـيل

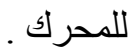


عند إجر اء الاختبار تم التأكد من قيمة تردد المصدر والذي هو 50 هرتز لان لان تحليل الإشـارة الصوتية المـأخوذة دائما

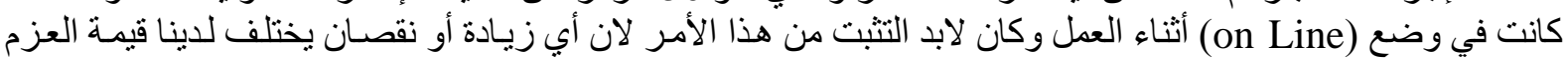

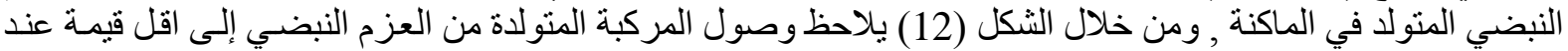

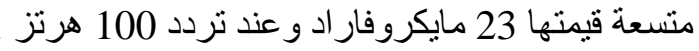

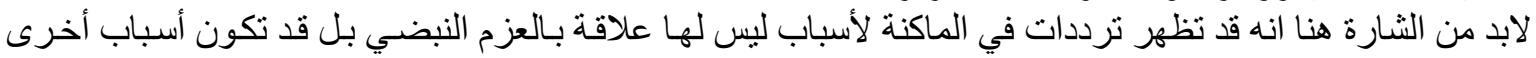

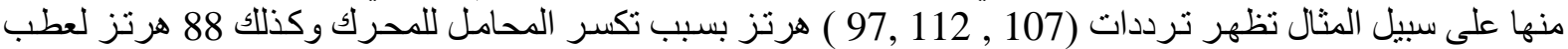

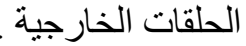

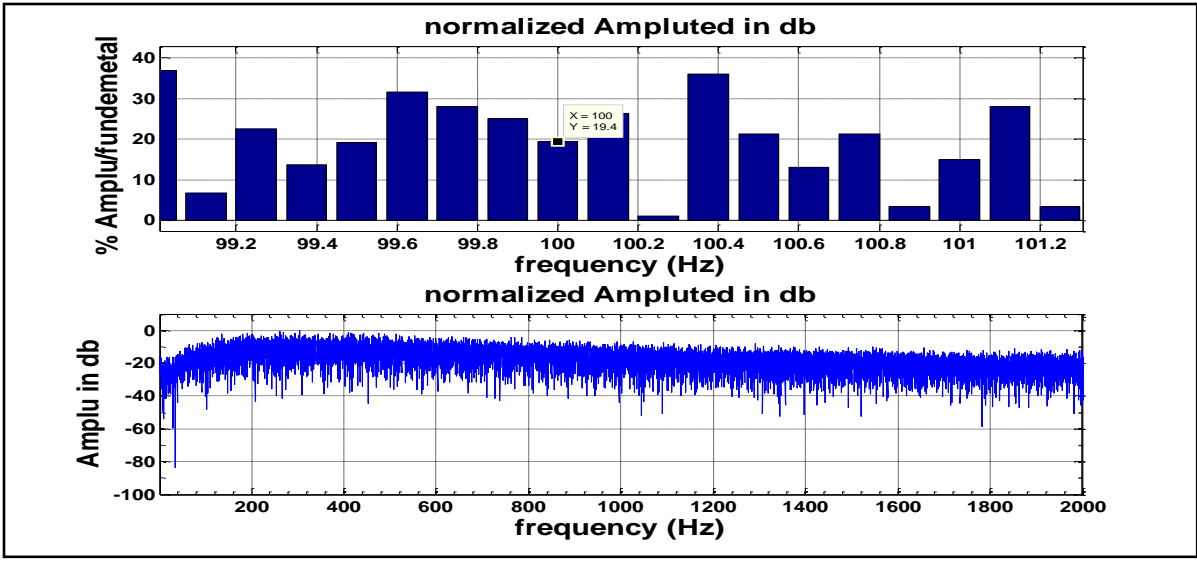

الثكل (11) تكبير لإشارة التحليل الصوتية لإيجاد المركبة المتولدة من العزم النبضي

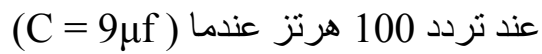

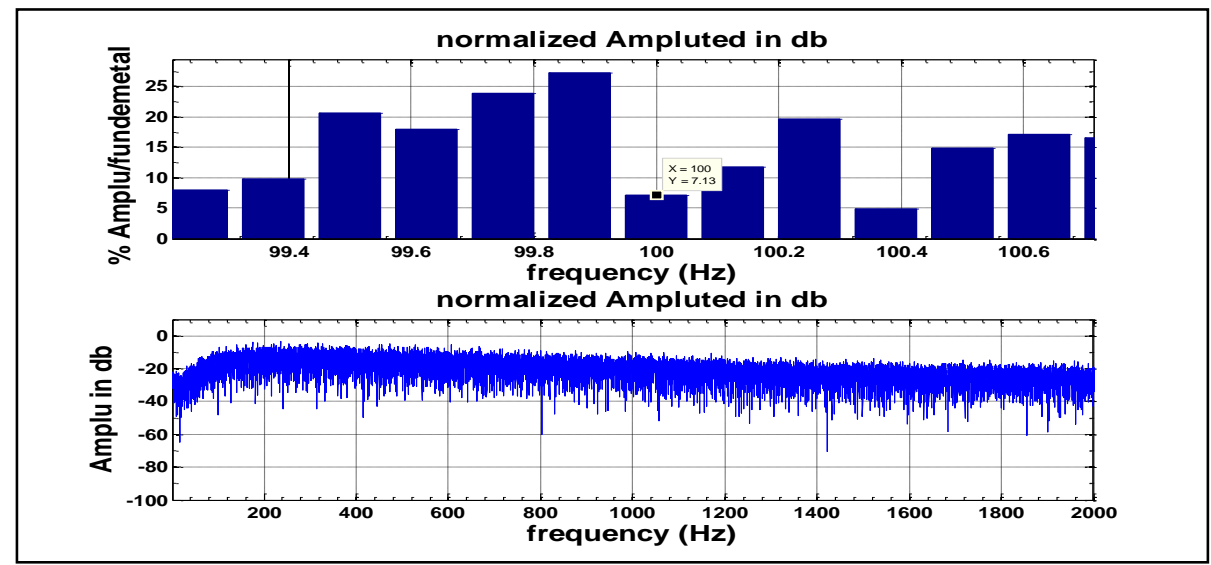

الثكل (12) تكبير لإشارة التحليل الصوتية لإيجاد المركبة المتولدة من العزم النبضي

عند تردد 100 هرتز عندما (C =

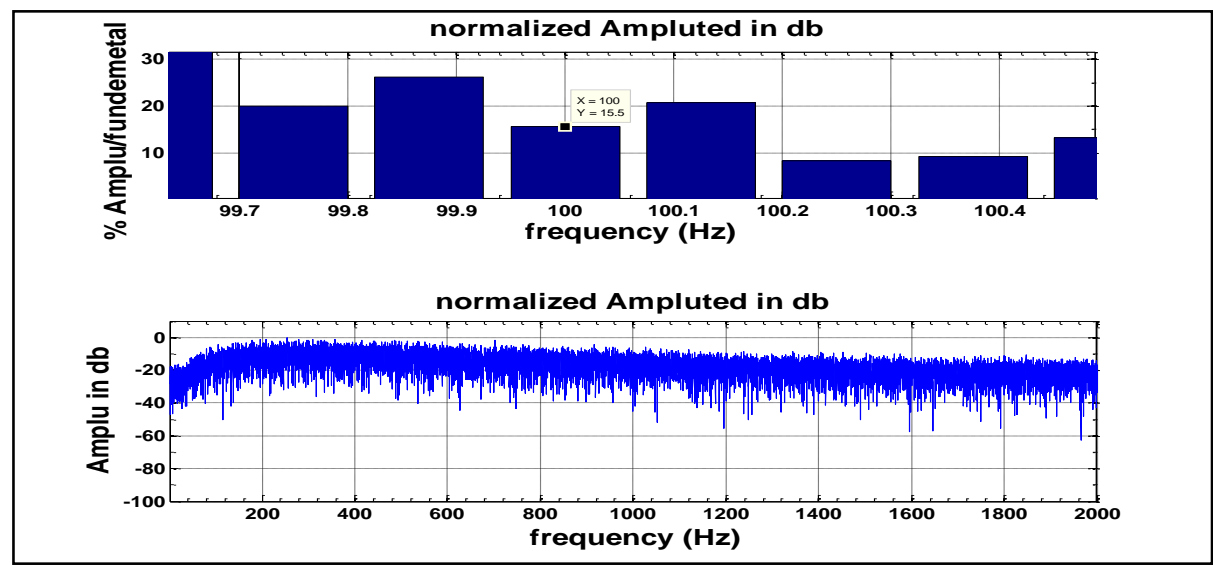




$$
\begin{aligned}
& \text { الثكل (13) تكبير لإشارة التحليل الصوتية لإيجاد المركبة المتولدة من العزم النبضي } \\
& \text { عند تردد } 100 \text { هرتز عندما (C) }
\end{aligned}
$$

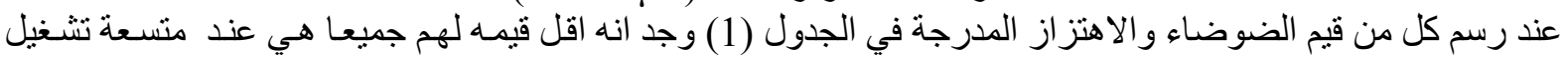
قدر ها 23 مايكروفار اد وكما يبينه الثكل (14).

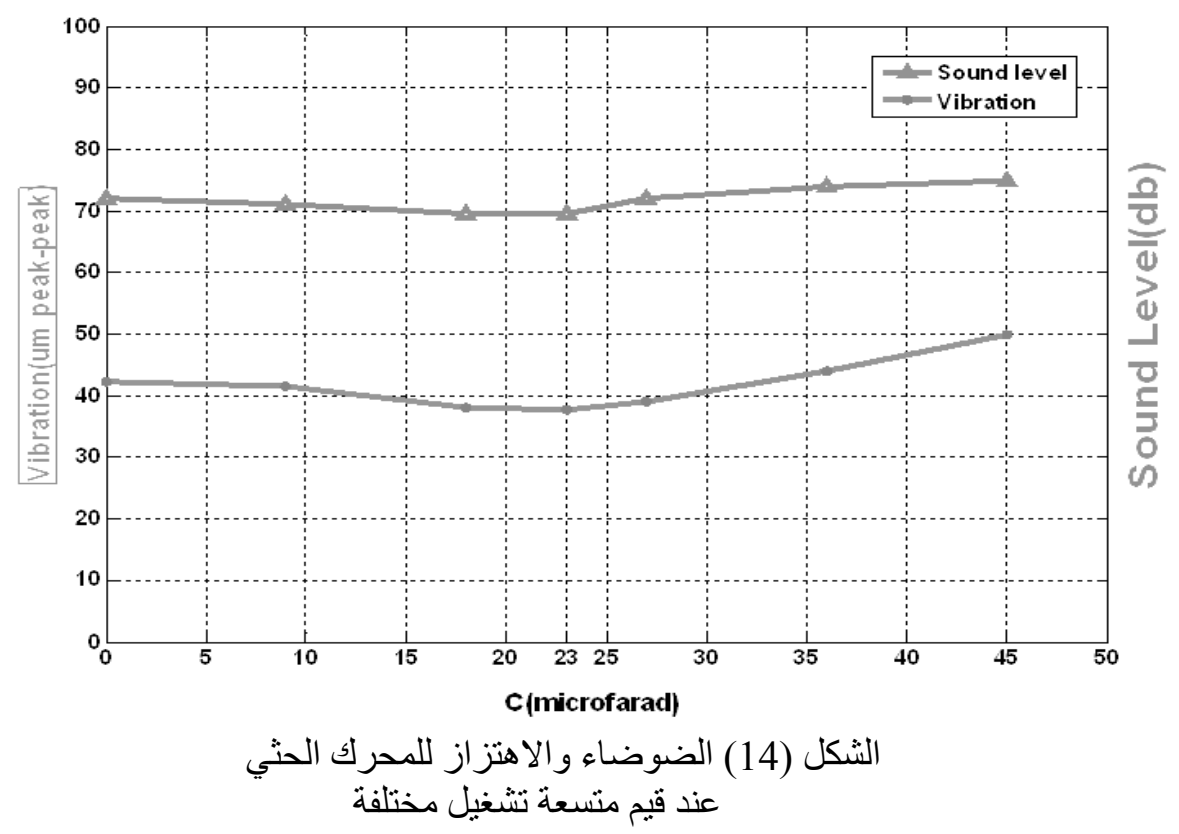

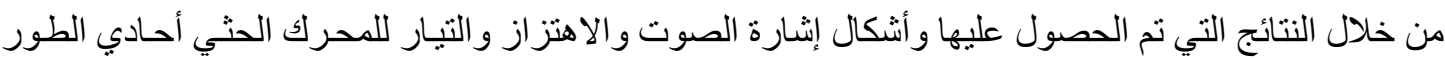

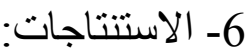

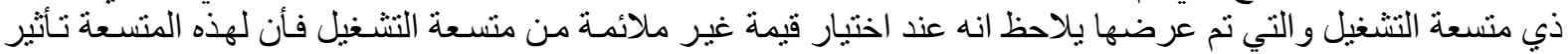

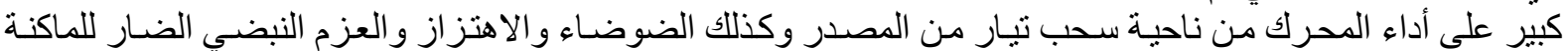
و الذي قد يصل إلى أربعة أضعاف قيمته فيما لو تم اختيار قيمة غير ملائمة من متسعة التشغيل.

ومن خلال البحث وتحليل الإشارة تم الكثف عن أن أفضل قيمة لمتسعة التشغيل لهذا المحرك هي بحدود 23

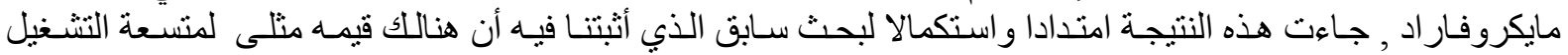

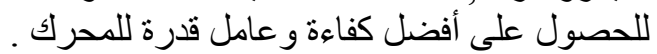

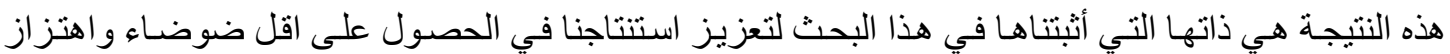

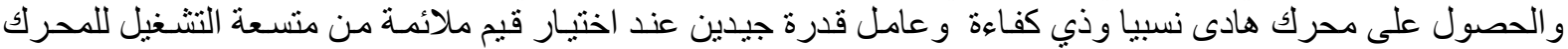

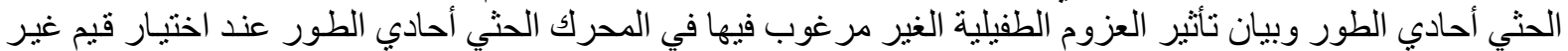

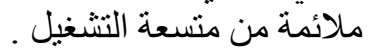

المصادر

1- Charles Kingsley, “ ELECTRICAL MACHINARY”, Sixth Edition 2003 , The McGraw-Hill Companies , Handbook.

2- Jacek F. Gieras . Chong Wang. Joseph Cho Lai,"Noise of Poly-phase Electric Motors".2006 Taylor \& Francis Group, LLC. Handbook.

3- E.Muljadi , Y. Zhao." Adjustable Ac Capacitor for a single phase induction motor'.IEEE.Trans.lnd.Appli.V.29,pp.479-485,1993. 
مديرية

$$
\begin{aligned}
& \text { 4- مكائن التيار المتناوب نأليف الأستاذ الدكتور باسل محدد سعيد والدكتور ضياء علي بشير النعمة. } \\
& \text { دار الكتب للطباعة والنشر, جامعة الموصل.(1989) }
\end{aligned}
$$

5- S.Vaez-Zadeh , H. Langari." High Average - Low Pulsating Torque Operation of single phase induction motor".IEEE.Trans.2000.

6- Lieven Vandevelde, Claus B. Rasmussen and A.A. Melkebeek "Numerical Analysis of Magnetic Noise and Torque Ripples of Spilt - Phase induction motor " . IEEE. Trans .2008.

7- Sebastiao Lauro Nau , Hugo Gustavo Gomez." Acoustic Noise In induction motor: Causes AND Solution".IEEE.Trans.PCIC-2000-26.

8- William R. Finley, Mark M. Hodowanec, Warren G.Holter." An Analytical Approach to Solving Motor Vibration Problems”.IEEE.PCIC-99-20.1999.

9- Dhiya AL-Nimma , Omar Sharaf Al-Deen , "Performance Analysis of a single phase induction motor For Different values of running Capacitor" journal of Tikreet Engineering , 2010 .

تم اجراء البحث في كلية ألهندسة = جامعة ألموصل 